\title{
RESENHA
}

\section{UM OLHAR SOBRE A TRAJETÓRIA POLÍTICA DE LEONEL BRIZOLA}

\section{UM OLHAR SOBRE A TRAJETÓRIA POLÍTICA DE LEONEL BRIZOLA}

Manoel Reinaldo Silva Rego

Professor de História da Rede Municipal de Ensino de

Vitória da Conquista

Sobre Leonel Brizola, já se tem uma considerável bibliografia. Como exemplo, podese mencionar "Brizolismo - Estetização da Política e Carisma", de João Trajano Santo-Sé, e "El Caudilho: Leonel Brizola - um perfil biográfico", de Francisco das Chagas Leite Filho, sendo este último uma biografia no sentido clássico. O primeiro é fruto de uma tese de doutorado em Ciência Política defendida na Universidade Federal do Rio de Janeiro; o segundo, uma publicação de um correligionário e assessor político.

Ao que parece, esses são os trabalhos mais completos sobre a atuação política de Leonel Brizola, embora a estetização da política abranja um período específico: quando o político gaúcho passa atuar no Rio de Janeiro, no retorno ao jogo democrático, no início da década de 1980.

Livro publicado em 2016 pela Civilização Brasileira, 348 páginas, “A Razão Indignada", compõe-se de uma coletânea de textos (artigos acadêmicos) que fazem parte de dissertações, teses ou comunicações apresentadas em congressos sobre a trajetória política de Leonel Brizola. Fiel ao título, os trabalhos selecionados pelos professores Jorge Ferreira e Américo Freire estão organizados em duas partes, abordando momentos distintos da trajetória de Brizola.

O livro ora resenhado não trata de uma trajetória de vida. Porém, demarca a direção do ator político em dois momentos distintos, apresentando a incidência da atuação deste personagem.

\begin{tabular}{|l|l|l|l|l|l|}
\hline Revista RBBA & ISSN 2316-1205 & Vitória da Conquista & V.7 $\mathrm{n}^{\text {o }} 1$ & p. 451-456 & Julho2018 \\
\hline
\end{tabular}


A primeira parte delimita entre 1961/1964 e contextualiza Brizola dentro do nacionalismo revolucionário, abordando o período de sucessivas crises políticas do início dos anos 60 do século passado, quando vários projetos estão em disputa, em tempos de Guerra Fria.

A Razão Indignada, na primeira coletânea de trabalho, mostra a atuação de um líder político regional que se torna o centro da arena política brasileira, com sua ação na defesa do nacionalismo, do trabalhismo e das reformas de base.

Isso foi possível depois que Brizola somou grande capital político no campo das esquerdas devido a duas atitudes, com sucesso, durante sua gestão frete ao governo do estado do Rio Grande do Sul.

A primeira delas consiste na encampação da subsidiária de eletricidade da Companhia Elétrica Rio-grandense, filial da Bond and Share, empresa estadunidense, somada à expropriação da Companhia Telefônica Rio-grandense, filial da ITT, também com sede nos EUA, depois de várias tentativas de acordo para continuidade de funcionamento da empresa.

A segunda foi a organização da resistência para dar posse ao vice-presidente eleito João Goulart como chefe do executivo nacional, depois da renúncia de Jânio Quadros, uma vez que setores das forças armadas e parte da elite política civil não queria empossá-lo.

Como menciona João Trajano Sento-Sé na apresentação do livro, Brizola é, para o autor, um fruto do contexto em que bandeiras como o nacionalismo, a autodeterminação de um povo e o anti-imperialismo tornaram-se conteúdo programático de várias agremiações partidárias de esquerda.

Os artigos publicados na primeira parte do livro, "Leonel Brizola e o tempo do nacionalismo revolucionário (1961-1964)", como já foi mencionado, é um esforço de entendimento da atuação de Brizola no pré-golpe de 1964.

O primeiro deles, assinado por Jorge Ferreira, intitulado "Nacionalismo, democracia e reformas: as ideias políticas de Leonel Brizola (1961-1964”), aborda, como sugere o próprio título, e o corpo teórico e doutrinário do trabalhismo defendido pelo político gaúcho no período delimitado. $\mathrm{O}$ autor contextualiza Brizola como um produto da Guerra Fria, atento às ideias da esquerda latino-americana da época e à doutrina social da igreja católica. Além disso, fazia uma leitura própria da carta testamento deixada por Getúlio Vargas. Este artigo tem como objetivo situar Brizola no campo intelectual da época e sua produção simbólica na vida política do país.

\section{Revista RBBA}


Seguindo a linha de entendimento mais específico sobre o nacionalismo revolucionário, complementam a primeira parte do livro três artigos sobre o grupo dos onze. O primeiro deles, "O povo nas ruas": Brizola chama a organização dos comandos nacionalistas”, da autoria militante de Carla Brandalise e Marluza Marques Harres constitui um esforço de entendimento da atuação de Brizola na organização política extrapartidária (ligada a setores do PTB). O objetivo do texto é fazer um posicionamento global sobre o perfil desses militantes políticos e levando em conta a atuação de Leonel Brizola no contexto.

Porém, por alguns motivos, a autora acabou concentrando sua análise no Rio Grande do Sul. O primeiro desses motivos seria a importância que tem este Estado como berço do trabalhismo e da trajetória de Brizola no cenário nacional. Também pode ser levado em conta que as pesquisadoras são filiadas a grupos de estudos com sede neste estado. As autoras apontam dados de estudo sobre processo envolvendo o grupo dos onzes no Rio Grande. A partir de gráficos (com quantidade de processo) faz uma análise buscando um entendimento sobre esta organização política, bem como aspectos dos envolvidos com a militância.

Direcionado a uma abordagem mais local está, também, o artigo de Tânia dos Santos Tavares, "Leonel Brizola e os nacional-revolucionários: o Grupo dos Onzes em Duque de Caxias, Rio de Janeiro (1963-1964)”. Esta autora busca compreender a atuação do Grupo dos Onzes e de Leonel Brizola na cidade citada, destacando como a rádio Radio Mayrink Veiga foi importante para a difusão da organização política. $\mathrm{O}$ artigo da pesquisadora, entre outras fontes, está ancorado em várias entrevistas com pessoas que participaram na época, do referido grupo.

Há, também, um artigo de Soanne Cristino Almeida dos Santos, denominado "A frente de mobilização popular em Una - Bahia (1963/1965)”. Una era, na época, uma pequena cidade com aproximadamente 18 mil habitantes. A autora explica como as transformações econômicas da cidade permitiram a chegada de várias pessoas e de ideias progressistas. $\mathrm{O}$ contexto foi propício para o declínio de um chefe político local, Manoel Almeida, que, juntamente com sua família, controlava, até o início da década de 60, os partidos políticos, entre eles o PTB, mesmo esse líder político sendo filiado à UDN.

Soanne apresenta como os objetivos da FMP, liderada por Brizola, tinham, na pequena cidade, caráter reformista e visava atender apenas reivindicações da política local. Porém, 
com o passar do tempo e a polarização da política nacional, os veículos de comunicação de FMP, em Una, também tendem a uma postura mais radical.

Liberalino Barbosa Souto, do Partido Democrático Cristão (PDC), que no início era receptível com a organização da Frente na cidade, passou a se incomodar com a situação, chegando ao ponto de proibir, no segundo semestre de 1963, o programa de Rádio " $A$ Mobilização Popular", mostrando o caráter conservador de sua gestão. Embora mais tarde ele venha a ser vitimado pela conjuntura do pós-golpe, sendo destituído do cargo, acusado de corrupção pelos adversários políticos apoiados pelos militares.

A rádio Radio Mayrink Veiga e o jornal O Panfleto, no âmbito nacional, eram os dois principais responsáveis pela divulgação da FMP. A audiência era tanta que algumas pessoas na cidade mencionada iam a um bar ouvir o que Brizola falava durante seu programa.

Em Una, o jornal $O$ Democrata e o programa de rádioAVoz da Frente faziam complemento da divulgação dos ideais e dos objetos da organização política, muita das vezes adaptando as reivindicações e bandeiras ao poder local.

O artigo de Gabriel da Fonseca Onofre, “As duas faces de Jango: as esquerdas trabalhistas de San Tiago Dantas e Brizola”, fecha a primeira parte do livro. Neste artigo, o autor foca sua análise nas duas esquerdas trabalhistas, e seu impacto no governo João Goulart.

Na segunda parte, "Brizola e o tempo do trabalhismo democrático (1979 - 2004)" analisa a atuação do estadista gaúcho na arena política brasileira do processo de abertura à retomada do jogo democrático.

O texto de um dos organizadores da obra, Américo Freire, “O fio da História: Leonel Brizola e a renovação da tradição trabalhista no Brasil contemporâneo (1980/1990)" abre a segunda parte do livro. Neste trabalho, o autor faz um panorama do contexto do retorno de Brizola à arena política fluminense, sua forma de atuação, utilizando-se dos famosos tijolaços em meios de comunicações, principalmente no Jornal do Brasil e de forma paga.

Por último, Américo Freire analisa a produção político-ideológica do líder trabalhista no contexto supracitado, tendo como principais referências os tijolaços e uma avaliação das eleições nacionais em que o político gaúcho participou.

O artigo de Michelle Reis de Macedo, “As esquerdas revolucionárias, Leonel Brizola e a refundação do trabalhismo", faz uma análise de como foi difícil para Leonel Brizola voltar a atuar na vida política depois de 15 anos de exílio. A autora levanta como outras correntes da esquerda, principalmente ligada ao PT e PC do B, apesar de fragmentada se sem 
coesão, conseguiram se unificar para combater o trabalhismo, do qual Brizola era seu maior representante.

Esse contexto foi mencionado, também, no livro "El Caudilho". F. C. Leite Filho faz alusões às tentativas fracassadas do político gaúcho de estabelecer um projeto comum com Lula e o PT.

Em seguida, faz parte do livro dois artigos sobre as gestões de Brizola no Rio de Janeiro. O primeiro deles, abordando a segurança pública, de autoria de Bruno Marques Silva, denominado "A segurança pública nos governos Leonel Brizola no governo do Rio de Janeiro (1983 - 1995). O autor aborda as reformas no comando da PMERJ (Polícia Militar do Estado do Rio de Janeiro), lideradas pelo coronel Carlos Magno Nazareth Cerqueira e seus colaboradores, na tentativa de construir novas formas de manutenção da ordem pública, preocupando-se com práticas policiais preventivas que ampliassem os espaços para o exercício da cidadania.

O segundo artigo, "Das Brizoletas aos Brizolões: a educação pública nos governos Brizola”, de autoria de Libânia Xavier, estende-se a um período mais extenso, abordando os governos de Brizola no Rio Grande do Sul e no Rio de Janeiro. Neste artigo, a autora comenta as ações da política daqueles governos para emplacar seu planejamento de campanha.

Se as Brizoletas marcaram o início da trajetória do político gaúcho, as escolas construídas no Rio de Janeiro (Brizolões) foram marcadas por grandes críticas por parte de seus opositores, muitas delas fundamentadas na perda da função da escola (de ensinar e não de assistir) ou de investimentos desnecessários, meramente demagógicos, para aglomerar votos.

Ambos os autores percebem a reação conservadora e a descontinuidade das políticas de segurança e educação por outras gestões que sucederam à Brizolista.

Encerra a coletânea um artigo de Ângela de Castro Gomes, "Brizola e o trabalhismo", no qual a autora faz uma analise da trajetória de Brizola, partindo da reflexão sobre o emblemático rito funeral do líder político, em 21 de junho de 2004. Para a autora, depois de Getúlio Vargas, Brizola tornou-se um dos políticos com maior clamor popular no cortejo fúnebre. No mesmo trabalho, a autora faz comentários sobre o trabalhismo como cultura política no Brasil Republicano, enquadrando Brizola neste contexto. 
Por último, o livro traz nos anexos documentos como o discurso de Brizola em 1961, durante a campanha pela legalidade da posse de João Goulart, e uma ficha de inscrição no Grupos dos Onze.

A Razão Indignada é um bom livro sobre Leonel Brizola em dois tempos: faz parte do renascimento do político como objeto de análise e serve para fazermos uma reflexão, em tempo de crise, sobre quais partidos políticos e políticos e profissionais perderam identidades sobre projetos que defendiam.

Pode- se discordar dos ideais e das ideais de Leonel Brizola, no todo ou em parte. Porém, não se pode questionar que esse indivíduo foi marcado por uma coerência de pensamento e ação durante toda a sua longa trajetória política: coerência que é uma das temáticas centrais da obra comentada.

\section{Referência}

FREIRE, A. A razão indignada: Leonel Brizola em dois tempos (1961-1964 e 1979 - 2004). Civilização Brasileira, Rio de Janeiro, 1ª Edição; 2016.

\section{Sobre o autor}

Manoel Reinaldo Silva Rego. Possui graduação em história pela Universidade Estadual do Sudoeste da Bahia (2006) e graduação em Pedagogia pela Universidade do Estado da Bahia (2001). Tem Especialização em Educação, Cultura e Memória (2010) e em História, Cultura, Política e Sociedade (2011), ambas pela Universidade Estadual do Sudoeste da Bahia. Atualmente é professor de História da Rede Municipal de Ensino de Vitória da Conquista. Endereço eletrônico: msilvarego6@gmail.com

Recebido: 15.01 .18

Aprovado: 22.03 .18 